\title{
Provide Consumers with What They Want on Word of Mouth Forums*
}

\author{
Yan Liu ${ }^{1}$, Dahai Dong ${ }^{2}$, Robert E. Burnkant ${ }^{3}$ \\ ${ }^{1}$ Department of Consumer Sciences, The Ohio State University, Columbus, USA; ${ }^{2}$ School of Management and Economics, Dalian \\ University of Techonology, Dalian, China; ${ }^{3}$ Fisher College of Business, The Ohio State University, Columbus, USA. \\ Email: liu.825@osu.edu, dongdh@dlut.edu.cn, burnkrant.1@osu.edu
}

Received February $3^{\text {rd }}, 2013$; revised March $9^{\text {th }}, 2013$; accepted March $15^{\text {th }}, 2013$

\begin{abstract}
Internet word-of-mouth (WOM) has a powerful impact on the consumer information search process. However, richness in information causes information overload. Consumers are not able to efficiently find the information they need among numerous and often redundant WOM postings and forums. As consumers become knowledgeable about WOM outlets, they may lower their search cost as they learn what kind of information to expect on various WOM forums. This conceptual paper develops research propositions to explain: 1) types of information consumers expect to see on different types of WOM forums, and 2) how expectations relate to satisfaction with WOM information and forums.
\end{abstract}

Keywords: Internet Word-of-Mouth (WOM); Construal Level Theory; Consumer/Marketer-Sponsored Forums; Expectation Consistency/Inconsistency; Satisfaction

\section{Introduction}

With the continuing development of the Internet, online information search has become more and more popular [1]. Among the different types of information online, word-of-mouth (WOM) has a powerful impact on consumers' purchase decision making [2]. Many people search word-of-mouth information online before they make their final purchase decisions and word-of-mouth can be used to confirm or change the decision they originally made.

However, richness in information causes a serious problem for consumers, which is information overload. Previous studies have shown that consumers are not able to efficiently find the information they need among the numerous and often redundant postings and forums $[3,4]$. More specifically, a 2008 report from IDC, a market research firm, reveals that the average time online users spend on the Internet is 32.7 hours a week; $20 \%$ of which is for information search. However, only $5 \%$ of the time that is spent for information search is considered to be effective and satisfactory. At the same time, some studies claim that as consumers become knowledgeable about word-of-mouth outlets, they may be able to lower their search cost since they will know what kind of information to expect in various word-of-mouth forums $[5,6]$.

\footnotetext{
*Supported by the Key Project of National Natural Sciences Foundation of China (No.70532006): "Innovation of Relationship Marketing Theory in the Internet Environment.”
}

However till now, online consumers' expectations for different word-of-mouth forums are still unclear. Moreover, it is necessary to understand the consequences (e.g., consumers' satisfaction with the word-of-mouth information or forums) after consumers' expectations are satisfied or not satisfied. Hence, the research questions for this study are: 1) what types of word-of-mouth information do consumers expect to see in different types of word-of-mouth forums? And 2) how do expectations relate to satisfaction with the word-of-mouth information and with the forums? The understanding of those wordof-mouth expectations and consequences will benefit online forum administrators in organizing their information outlets and improving their information quality.

\section{Literature Review \& Research Propositions}

\subsection{Characteristics of Internet Word-of-Mouth Information}

Internet Word-of-Mouth is defined as "the behavior of consumers' sending their own positive or negative opinion or experiences of products or companies to other consumers, via the forum or chat" [7]. It can also be called eWOM (electronic Word-of-Mouth) or oWOM (online Word-of-Mouth). Internet Word-of-Mouth (abbreviated "WOM" in the following sections) is one type of information on the Internet and the content quality determines its effectiveness. As is claimed by Goldsmith 
and Horowitz (2006), content quality is curial for Internet Word-of-Mouth since no body language or other visible aids are available compared with the traditional wordof-mouth that is face-to-face [8,9]. Hence, it is agreed that the higher content quality the WOM information has, the more influential it is $[10,11]$.

Research has shown that WOM exhibits specific characteristics in content that attract consumers' attention and impact consumers' subsequent decision making [12]. In addition, researchers have found that the stronger characteristics in WOM are, the greater impacts WOM has on consumers' decision making [13-16]. A review of previous studies on WOM characteristics reveals that the following characteristics have been extensively studied and considered to be influential in consumers' purchase decision making. They are concreteness, vividness, attitude strength, informativeness and reliability.

The first two key characteristics are concreteness and vividness. Previous research claims that compared with abstract and pallid WOM, concrete and vivid WOM is inherently interesting, attention drawing and thought provoking and is therefore likely to have a stronger effect on the WOM receivers' memory and judgment [16-18]. Research also indicates that vividly presented WOM is more accessible from memory and is weighed more heavily in judgment $[19,20]$, because as information accessibility increases, the likelihood that this information is used as input for judgment and choices also increases [21]. Moreover, in an empirical study, Gremler (1994) finds that messages have more impact when delivered enthusiastically. Hence, negative WOM is more easily to be remembered since it is more vivid and always stated in details about the negative experiences [22].

The third characteristic is the attitude strength of WOM. WOM can be positive, neutral or negative; however, only extremely positive or negative WOM can be remembered and perform effectively in persuasion [13,22, 23]. Research reveals that when coupled with strong message arguments, real-life experiences can enhance message elaboration and increase persuasion [24,25]. Thus, researchers believe that WOM presenting a strong attitude will increase the strength and speed of consumers' approach or avoidance decisions relative to WOM not presenting a strong attitude [26,27]. Additionally, Lau and Ng (2001) suggests that negative WOM is commonly more influential because unpleasant experiences usually generate extremely strong negative attitude [18].

The fourth characteristic is informativeness. Word-ofmouth is an important source of information to consumers, regarding products, services, brands or companies. Consumers use WOM to guide their purchase only when there is valuable information that aids their decision making $[28,29]$. Thus, whether or not WOM is informative matters; only WOM with useful information will attract consumers' attention because they seem reliable. Hence, the last and most important characteristic is reliability. Much research on WOM indicates that trust is one of the most essential factors for WOM [29-31]. Due to the weak ties between people on the Internet, WOM lacks of trust and seems less effective in guiding others' decision compared with traditional WOM that is between strong-tie people [32]. Previous studies have identified the following situations in which WOM is considered reliable: 1) WOM sent by experts or opinion leaders [33,34]; 2) WOM from senders with higher virtual status (such as discussion board administrator) [32]; 3) WOM that is extensively discussed, i.e., many feedback messages and follow-ups are received [9]; 4) WOM from people who have previously sent similar WOM [31]; 5) WOM from people who are always active in this forum [31]; 6) WOM from people who are perceived to have similar interests, or similar in age, gender, education or occupation [34]; and 7) WOM about senders' personal experience and feelings [29]. It is believed that only WOM that is considered to be reliable because of one or more of the reasons listed above will serve as an effective guider for its receivers' decision making.

\subsection{Dual Processing of WOM Information}

As discussed above, there are five essential characteristics in WOM information that determine the effectiveness of WOM. They are concreteness, vividness, attitude strength, informativeness and reliability. These characteristics of WOM are important because they influence the persuasiveness of WOM; thereby affecting consumers' information processing and decision making.

Among the numerous information-processing models, dual-process models have a long history in the social sciences for improving understanding of information processing. Since Deutsch and Gerrard proposed dual-process theory in 1955, researchers have been investigating people's dual processing of information in various contexts, such as neighborhoods, university settings, and workplace communities, all of which have demonstrated the significant role of dual processing in information [35, 36]. More recent psychological models have distinguished between a rapid, automatic, effortless, associative, intuitive process (System 1), and a slower, rule-governed, analytic, deliberate, effortful process (System 2) [36]. System 1 is emotional processing and System 2 is cognitive processing. Previous research indicates that the cognitive processing and emotional processing in the dualprocess model can successfully explain how different types of WOM or different characteristics of WOM affect the persuasiveness of WOM [31]. Cognitive processing refers to the process in which people rely on information obtained as evidence about reality to make self-judgment. Hence, relevant components, such as use- 
fulness of information, source creditability or content creditability are important triggers of cognitive processing $[31,37]$. On the other hand, emotional processing refers to the process in which people rely not so much on the informational portion of the WOM; instead, the strength of others' opinions or the way the messages are conveyed generate receivers' emotions. Hence, relevant components, such as argument strength of WOM, or whether WOM is vividly conveyed are important triggers of emotional processing $[31,38]$.

Therefore, it is logical to propose that concrete and vivid WOM and WOM with a strong positive or negative attitude will induce rapid, automatic and effortless perception, which is consistent with System 1 processing. Because concrete, vivid and strong attitude WOM information is explicit, allowing consumers to make intuitive judgments [39]. Intuitive judgments are rapid, automatic and effortless [40]. In contrast, informative and reliable WOM information will induce slower, analytic, deliberate and effortful perceptions, which is consistent with System 2 processing. These WOM characteristics are implicit and therefore, consumers judge and analyze the information more precisely. Deliberate and analytical decisions are time and effort consuming [37].

\subsection{Marketer-Sponsored WOM Forums vs. Consumer-Sponsored WOM Forums}

The rapidly growing popularity of online forums has enabled both marketers and consumers to build and promote consumer-brand and consumer-company relationships [41]. Among the numerous online forums, marketer-sponsored WOM forums and consumer-sponsored WOM forums are two distinct types of online WOM outlets [42]. A marketer-sponsored forum is set up and maintained by a company. Consumers can contribute WOM information, but the marketer has the power to add or delete messages. In such online forums, marketers can facilitate the forums as a versatile brand-building tool so that they can create, customize, and distribute persuasive advertising messages for products and services [41]. Examples for marketer-sponsored forums are forums appearing on official company websites, such as the Canon IXUS970 forum, where these cameras are displayed, introduced and discussed.

A consumer-sponsored forum is set up and maintained by a third-party organization. Consumers can post WOM in the forums, while marketers cannot add or delete messages. In such online forums, consumers can also build and manage many successful online forums in which they can lead other members to engage voluntarily in various forums behaviors, such as membership intention, recommendation, active participation, and so forth [41]. Examples for consumer-sponsored forums are forums providing rankings or price comparisons, such as forums appearing on Epinions.com.

The most outstanding differences between marketersponsored forums and consumer-sponsored forums are 1) the identity and allegiance of the forum administrator and 2 ) the identities of the WOM contributors. In a marketersponsored forum, the marketer is in charge of the forum and has the power to add and/or delete any message; consumers are participants and only have the ability to submit opinions and experiences that will be considered for posting in the forum. When consumers are exposed to the marketer-sponsored WOM forums, they view marketers' effort to create and manage forums as a type of sponsorship whose primary objective is to increase sales profit indirectly by enhancing the image of the company [42]. Accordingly, consumers are more likely to associate the marketer's effort with extrinsic motives of profit exploittation or, at best, company image enhancement.

By contrast, when consumers are exposed to the consumer-sponsored WOM forums, since it is known that a third-party organization is in charge of the website and only rarely adds or deletes messages exist, consumers are willing to be active participants with freedom to say anything they would like to say. For other consumers who search for information in the forums, they expect to learn more about others' opinions because opinions here seem more reliable and less marketing-oriented. Furthermore, in consumer-sponsored forums, consumers can be empowered to be administrators in some chat rooms or forums; in this way, they are given the power to push important postings to the top of the board, which means they can put more weight on WOM that they think is important.

\subsection{Relative Social Distance on Marketer-Sponsored WOM Forums vs. Consumer-Sponsored WOM Forums}

WOM characteristics influence consumers' perceptions of WOM; in addition, social distance contributes to the formation of consumers' perceptions. Social distance is one of the four key elements of psychological distance in the Construal Level Theory (CLT), which has been studied extensively since the 21st century. Nowadays this theory is widely applied to explain consumers' psychological issues in marketing context.

According to Construal Level Theory (CLT), individuals use concrete, low-level construals to represent near events and abstract, high-level construals to represent distant events. Low-level construals are relatively unstructured, contextualized representations that include subordinate and incidental features of events. In contrast, high level construals are schematic, decontextualized representations that extract the gist of an event from the available information. These construals consist of a few superordinate core features of events. Thus, whereas re- 
presentations of near future events are rich in details, some of which are incidental or peripheral, representations of distant events achieve abstraction by omitting secondary and incidental features [43].

CLT's basic premise is that the more psychologically distant an event is, the more it will be represented at higher levels of abstraction. There are four dimensions of psychological distance; they are time, space, social distance, and probability. For the time dimension, many studies have examined the hypothesis that distant future events are represented in a more abstract, structured, high-level manner than near future events $[37,44]$. For the space dimension, a number of studies have established a link between spatial distance and mental construal. In a spatially distant condition, the event is likely to be considered more abstract and simply-structured than that in a spatially near condition $[45,46]$.

For the social distance dimension, there are two sources of social distance: lack of similarity and power inequality. It is found that behavior performed by a dissimilar other would be represented at a higher level of construal than behavior performed by a similar other [43] and elevated power would increase the psychological distance one feels from another [47]. For the probability dimension, the main research stream has argued that the lower the probability of an event, the greater is its psychological distance [37].

Understanding consumers' perceptions of psychologycal distance on the Internet is an area that has not been widely explored in the literature [37]. Generally, the literature reviewed about the social distance in the CLT suggests that when a consumer searches WOM in a marketer-sponsored WOM forum, they will perceive great psychological distance. This is because great dissimilarity with the marketer and a large power distance between the consumer and the marketer would be perceived. Therefore, far psychological distance would induce higher levels of construal. In contrast, when a consumer enters a consumer-sponsored WOM forum, he/she will perceive great similarity, because the administrator is also a consumer; and more power would be given if he/ she wishes to engage in the discussion. Thus, the perceived psychological distance would be smaller and lower levels of construal are induced.

Another popular topic in social distance that is relevant to high vs. low levels of construals is self-control. Fujita et al. (2006) propose that feelings of self-control increase when people are able to make decisions and behave in a manner consistent with high-level versus lowlevel construals of a situation. More specifically, activation of high-level construals should lead to greater feelings of self-control and activation of low-level construals should lead to feelings of less self-control. Hence, in marketer-sponsored WOM forums, due to far psycho- logical distance, consumers have high levels of construals so they feel the need for greater self-control. Thus, in order to achieve greater self-control, they need to process information via their cognitive system and informative and reliable WOM is needed to activate that processing. In contrast, in consumer-sponsored WOM forums, consumers have low levels of construals due to close psychological distance and they feel less self-control; therefore, they would process information via their affective system. The reason is that people prefer affective processing when cognitive processing is not necessary; since no extra effort is willing to be paid when lack of selfcontrol [46]. Thus, WOM that is concrete and vivid and presents a strong attitude is needed in consumer-sponsored WOM forums.

Therefore, it is proposed in this study that before entering online forums, consumers with prior online experience will have some expectations about the WOM they will find. And their expectations will become stronger after they enter specific forums, because search experience helps activate their needs [48]. When consumers enter marketer-sponsored WOM forums, they will expect to see more informative and reliable WOM; after experiencing the forums, their expectations for informative and reliable WOM will increase. When consumers enter consumer-sponsored WOM forums, they will expect to see WOM that is concrete, vivid and strong in attitude; after experiencing the forums, their expectations for such WOM will become stronger. Hence, Propositions 1 and 2 are shown as follows.

P1: Consumers expect informative and reliable WOM in marketer-sponsored WOM forums and their expectations strengthen after browsing the forums.

P2: Consumers expect concrete, vivid and strong in attitude WOM in consumer-sponsored WOM forums and their expectations strengthen after browsing the forums.

\subsection{WOM Expectation and Satisfaction}

One of the most widely used and accepted theories in investigating expectations and satisfaction is Expectation-Disconfirmation Theory (EDT), which was proposed by Oliver $(1977,1980)$ [49,50]. It has been applied in many fields, including marketing and consumer behavior (e.g., Kopalle \& Lehmann, 2001; Szymanski \& Henard, 2001) [51,52], service quality (e.g., Walker, 1995; Kettinger \& Lee, 2005) [53,54], psychology (e.g., Phillips \& Baumgartner, 2002) [55], and human resources (e.g., Hom et al., 1998, 1999) [56,57]. EDT posits that satisfaction is a function of prior expectations and disconformation; and satisfaction is a key determinant of repurchase intentions [50,58,59]. In this theory, expectation is defined as a set of pre-exposure beliefs about the product; disconfirmation is the discrepancy between ex- 
pectations and actual experiences. Better-than-expected outcomes lead to positive disconfirmation and worsethan-expected outcomes lead to negative disconfirmation. Consumers are satisfied in the case of positive disconfirmation and dissatisfied in the case of negative disconfirmation [58,59]. The causal flow is shown in Figure 1: 1) exposure to information about a product's performance characteristics leads to the formation of product specific beliefs or expectations of the consumer; 2) a cognitive comparison between expectations and actual experiences leads to a subjective calculation of disconfirmation; 3) a combination of expectations and disconfirmation determines the satisfaction level that, in turn, influences repurchase intentions; and 4) expectations are also direct determinants of satisfaction [58,59].

Another important theory that emphasizes satisfaction and involves expectations is Motivator-Hygiene Theory (also known as Two-Factor Theory). It was proposed by Herzberg, Mausner and Snyderman in their book of The Motivation to Work (1959) and has been widely used in the field of human recourse to investigate employees' job satisfaction (e.g., Locke \& Whiting, 1974; Knoop, 1994) [60,61]. The Motivator-Hygiene Theory demonstrates that people have two separate and independent need systems that do not interact. The first of these, the motivator continuum, deals with people's need for psychological growth. This need is met on the job through intrinsic job factors such as achievement, recognition, responsibility, opportunity for growth, and enjoyment of the work itself. It is the motivator factors that provide people with job satisfaction. The hygiene continuum deals with people's need to avoid pain from his environment and is met by increasing extrinsic job factors such as salary, status, company policy and administration, good interpersonal relationships, etc. It is the hygiene factors that keep people from states of dissatisfaction. Thus, explicit to motivator-hygiene theory is the hypothesis that satisfaction and dissatisfaction are separate and independent conditions of job attitudes. The opposite of "satisfaction" is not "dissatisfaction"; instead, it is "no satisfaction". Similarly, the opposite of "dissatisfaction" is not "satis- faction"; it is "no dissatisfaction" [62] (see Figure 2).

Based on the Motivator-Hygiene Theory, it is clear that the determinant of customer satisfaction is expectations. Customer expectations are a set of pre-exposure beliefs about the product or companies' performance [58,

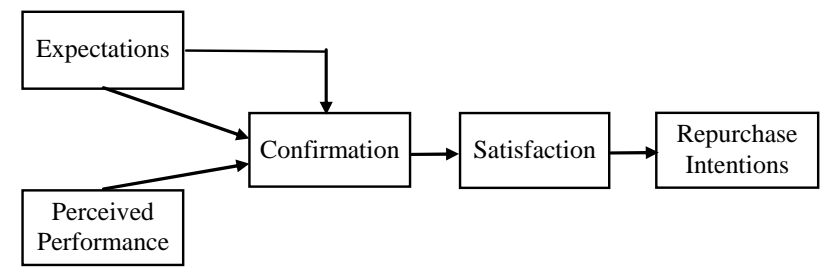

Figure 1. The expectation-disconfirmation model.

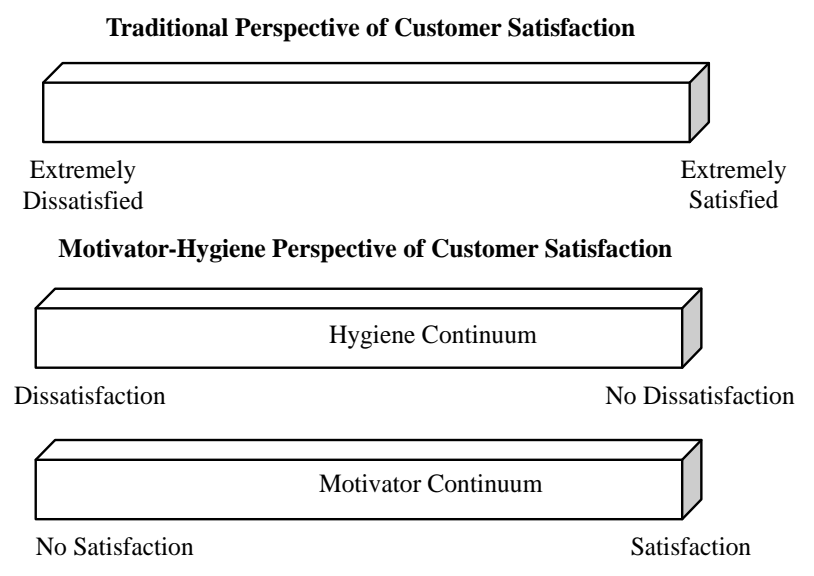

Figure 2. Contrasts of two perspectives of customers satisfaction.

59]. Even though the products and service from companies are of good quality, customers will not be satisfied if they are not within the customers' pre-exposure beliefs. In other words, the presence of motivator factors can generate customer satisfaction; the presence of hygiene factors can only prevent customer dissatisfaction. In the context of this study, it is important that certain forums provide the expected WOM characteristics, so that customer satisfaction can be obtained. Otherwise, unexpected WOM characteristics can only prevent dissatisfaction, instead of developing satisfaction. More specifically, as it is proposed in P1 and P2 that consumers expect informative and reliable WOM in marketer-sponsored WOM forums and expect concrete, vivid and strong in attitude WOM in consumer-sponsored WOM forums. Based on the Motivator-Hygiene Theory, it is clear that in marketer-sponsored WOM forums, informativeness and reliability of WOM are motivator factors that contribute to consumers' satisfaction; other characteristics, such as concreteness and vividness and strong in attitude are hygiene factors. By contrast, in consumer-sponsored WOM forums, concreteness, vividness and strong in attitude of WOM are motivator factors that contribute to consumers' satisfaction; other characteristics, informativeness and reliability, are hygiene factors. Therefore, in marketer-sponsored WOM forums, consumers should be provided by WOM that is informative and reliable; and in consumer-sponsored WOM forums, consumers should be provided by WOM that is concrete, vivid and strong in attitude.

By integrating the Expectation-Disconfirmation Theory (EDT) and the Motivator-Hygiene Theory, we propose the relationships between consumers' expectations on WOM characteristics and their satisfaction. When consumers search WOM in marketer-sponsored and consumer-sponsored WOM forums, it is expected that consumers have expectations about the characteristics of WOM they will find in different forums during the 
search process. If the characteristics of WOM they encounter are the same as those they expect (i.e., expectation consistency), they will feel satisfied; otherwise (i.e., expectation inconsistency), they will feel dissatisfied.

It is important to note that performance of both the WOM content and the forum will be evaluated by consumers. Walker (1995) proposed that satisfaction with pre-transaction service is perceived separately from satisfaction with transaction and post-transaction experiences; in addition, satisfaction with pre-transaction service affects satisfaction with core service, which affects satisfaction with post-transaction service [53]. Following his logic, consumers will distinguish between satisfaction/dissatisfaction with WOM information and forums that provide WOM. Because WOM information is preexpected by consumers before they enter the WOM forums; however, whether forums provide "right" WOM can only be perceived once consumers enter WOM forums. Therefore, we may see differences in satisfaction/ dissatisfaction with marketer-sponsored forums verse consumer-sponsored forums depending on whether or not the WOM provided has the "right" characteristics expected by the consumer.

In marketer-sponsored forums, marketers are professional information providers, who are expected to know all information about products and services. Marketers are also expected to select and organize all kinds of WOM from companies and from consumers in proper outlets [42], which can enhance the efficiency and effectiveness of consumers' information search and decision making. Based on the reasoning of $\mathrm{P} 1$, consumers expect to see informative and reliable WOM in marketer-sponsored WOM forums. They will feel extremely satisfied with WOM information if their expectations are satisfied (i.e., expectation consistency), because their decisionmaking is effectively assisted by the informative and reliable WOM information. At the same time, they will also show satisfaction towards marketers ${ }^{1}$. However, satisfaction with companies will be weakened because consumers consider it is the responsibility of companies to assist consumers' purchase by providing helpful information [63]. Moreover, aiding consumers' information search and facilitating purchases will profit their own companies [30]. Thus, when there is expectation consistency, consumers will show mild satisfaction towards companies. Based on the similar logic, it is expected that when consumers' expectations for informative and reliable WOM are not satisfied (i.e., expectation inconsistency), consumers will feel dissatisfied with

\footnotetext{
${ }^{1}$ Since consumers cannot distinguish marketers from companies or forums in marketer-sponsored forums because marketers from companies administrate the forums. Hence, we do not differentiate among satisfaction with marketers, satisfaction with companies and satisfaction with forums, in the marketer-sponsored forums. Thus, in order to be consistent, we use "satisfaction with companies" in common.
}

WOM information and the company. But the satisfaction with the company will be much more extreme because consumers think companies do not fulfill their job in assisting consumers' information search and purchase [63], which is their basic responsibility and serves for generating their own profits.

In consumer-sponsored forums, consumers will also be satisfied when there is expectation consistency and be dissatisfied when there is expectation inconsistency. However, since the administrators are not professional marketers but normal consumers or people from non-profit third-party organization, consumers' satisfaction is influenced dramatically due to the changes in administrators' identities. More specifically, when consumers' expectations for concrete, vivid and strong in attitude WOM information are satisfied, which facilitates their information search and decision making, they will appreciate the effective and helpful aids provided by those non-professional administrators; thereby inducing extreme satisfaction towards WOM forums. However, towards WOM information itself, they will show mild satisfaction because of their perceptions of motivation of those WOM information senders. For example, when receiving negative WOM information, consumers will perceive the anger and anxiety relief motivation of the senders [64], which induces the weakening of their satisfaction with WOM information itself. By contrast, when consumers' expectations for concrete, vivid and strong in attitude WOM information are not satisfied, they will feel dissatisfaction with WOM information and forums. Their dissatisfaction with WOM information will be more extreme, because they consider that senders' satisfying their own motivations induces the lack of possible and essential WOM characteristics which are useful for receivers [64,65].

Therefore, the following propositions are presented.

P3: In marketer-sponsored forums, if there is expectation consistency, consumers will feel extremely satisfied with WOM and mildly satisfied with the company.

P4: In marketer-sponsored forums, if there is expectation inconsistency, consumers will feel extremely dissatisfied with the company and mildly dissatisfied with WOM.

P5: In consumer-sponsored forums, if there is expectation consistency, consumers will feel extremely satisfied with the forum and mildly satisfied with WOM.

P6: In consumer-sponsored forums, if there is expectation inconsistency, consumers will feel extremely dissatisfied with WOM and mildly dissatisfied with the forum.

\section{Discussions}

The expected findings of this study are interesting and important for several reasons. First, they suggest that 
consumers do have different expectations about types of WOM information that appears on different types of forums. If the propositions are supported, they indicate that consumers' expectations for WOM are forum-specific: in marketer-sponsored forums, consumers expect informative and reliable WOM; on consumer-sponsored forums, consumers expect concrete, vivid WOM that is strong in attitude. If these are supported, it behooves WOM forums to take steps to determine the type of WOM information that their target users expect to find. Thus, findings might suggest that company or forum administrators should understand specific consumers' expectations about WOM information and post or organize WOM accordingly.

If the propositions relating to satisfaction are supported, then type of WOM posted on an online forum relative to type expected by consumers is critical because posting unexpected WOM will likely lead to consumer dissatisfaction and this problem could be serious for both marketer-sponsored forums and consumer-sponsored forums. Thus, the expected results would suggest that WOM plays different roles on different forums and that satisfaction is dependent on the extent to which the posted WOM matches WOM expected by consumers.

Support for the propositions would extend application of Construal Level Theory to the online environment, specifically the context of WOM. Construal Level Theory provides a unique perspective for understanding different consumer expectations about type of WOM found on different types of forums, that is, the difference in psychological distance. The theory also suggests ways to change the relative psychological distance: by changing consumer perceptions of similarity and power on the WOM forum. By using similarity and power appropriately, WOM forums could more effectively serve their customers in their information search processes.

Future studies should explore the relationships between satisfaction with WOM, company and forum, as well as between trust and WOM, company and forum. For example, does satisfaction/trust with WOM induce satisfaction with a company's WOM forum? And will that linkage induce satisfaction/trust with the company itself? Empirically exploring factors that mediate and moderate the satisfaction/trust process will benefit companies in their forum construction and development processes. And the same is likely to be true for consumersponsored forums.

\section{REFERENCES}

[1] S. Kulviwat, C. Guo and N. Engchanil, "Determinants of Online Information Search: A Critical Review and Assessment," Internet Research, Vol. 14, No. 3, 2004, pp. 245-253. doi:10.1108/10662240410542670

[2] J. Harrison-Walker, "The Measurement of Word-of-Mouth
Communication and an Investigation of Service Quality and Customer Commitment as Potential Antecedents,” Journal of Service Research, Vol. 4, No. 1, 2001, pp. 60-75. doi:10.1177/109467050141006

[3] L. R. Klein and G. T. Ford, "Consumer Search for Information in the Digital Age: An Empirical Study of Prepurchase Search for Automobiles,” Journal of Interactive Marketing, Vol. 17, No. 3, 2003, pp. 29-49. doi:10.1002/dir.10058

[4] E. J. Johnson, W. W. Moe, P. S. Fader, S. Bellman and G. L. Lohse, "On The Depth and Dynamics of Online Search Behavior,” Management Science, Vol. 50, No. 3, 2004, pp. 299-308. doi:10.1287/mnsc.1040.0194

[5] A. Ardichvili, V. Page and T. Wentling, "Motivation and Barriers to Participation in Virtual Knowledge-Sharing Communities of Practice," Journal of Knowledge Management, Vol. 7, No. 1, 2003, pp. 64-77. doi:10.1108/13673270310463626

[6] M. Wasko and S. Faraj, "Why Should I Share? Examining Social Capital and Knowledge Contribution in Electronic Networks of Practice,” MIS Quarterly, Vol. 29, No. 1, 2005, pp. 35-57.

[7] D. Bussiere, "Evidence and Implications of Electronic Word-of-Mouth,” In: H. E. Spotts and H. L. Meadow, Eds., Developments in Marketing Science: Vol. 23. Proceedings of the 23th Annual Conference of the Academy of Marketing Science, The Academy, Montreal, 2000, p. 361.

[8] D. Godes and D. Mayzlin, "Using Online Conversations to Study Word-of-Mouth Communication,” Marketing Science, Vol. 23, No. 4, 2004, pp. 545-560.

doi:10.1287/mksc.1040.0071

[9] K. D. Grantham, "Updating of Consumer Beliefs: The Influence of Majority/Minority Status on Consumers' Use of Word-of-Mouth Information,” Ph.D. Thesis, Duke University, Durham, 2001.

[10] S. Senecal and J. Nantel, "The Influence of Online Product Recommendations on Consumers' Online Choices," Journal of Retailing, Vol. 80, No. 2, 2004, pp. 159-169. doi:10.1016/j.jretai.2004.04.001

[11] A. T. Alon, "Rediscovering Word-of-Mouth: An Analysis of Word-of-Mouth Talk in the Context of Online Communities,” Ph.D. Thesis, Boston University, Boston, 2005.

[12] A. Armstrong and J. Hagel, "The Real Value of Communities,” Harvard Business Review, Vol. 74, No. 3, 1996, pp. 134-140.

[13] E. W. Anderson, "Customer Satisfaction and Word of Mouth," Journal of Service Research, Vol. 1, No. 1, 1998, pp. 517. doi:10.1177/109467059800100102

[14] P. Kiecker and D. Cowles, "Interpersonal Communication and Personal Influence on The Internet: A Framework for Examining Online Word-of-Mouth,” Journal of Euromarketing, Vol. 11, No. 2, 2001, pp. 71-88. doi:10.1300/J037v11n02_04

[15] D. Lemus, D. R. Seibold, A. J. Flanagin and M. J. Metzger, "Argument and Decision Making in Computer-Mediated Groups,” Journal of Communication, Vol. 54, No. 2, 2004, pp. 302-320. 
doi:10.1111/j.1460-2466.2004.tb02630.x

[16] J. C. Sweeney, G. N. Soutar and T. Mazzarol, "Factors Influencing Word of Mouth Effectiveness: Receiver Perspectives,” European Journal of Marketing, Vol. 42, No. 3-4, 2008, pp. 344-364. doi:10.1108/03090560810852977

[17] P. M. Herr, F. R. Kardes and J. Kim, "Effects of Wordof-Mouth and Product-Attitude Information on Persuasion: An Accessibility-Diagnosticity Perspective," Journal of Consumer Research, Vol. 17, No. 4, 1991, pp. 454-462. doi:10.1086/208570

[18] G. T. Lau and S. Ng, "Individual and Situational Factors Influencing Negative Word-of-Mouth Behavior," Canadian Journal of Administrative Sciences, Vol. 18, No. 3, 2001, pp. 163-178. doi:10.1111/j.1936-4490.2001.tb00253.x

[19] J. Kisielius and B. Sternthal, "Examining the Vividness Controversy: An Availability-Valence Interpretation,” Journal of Consumer Research, Vol. 12, No. 4, 1986, pp. 418431. doi:10.1086/208527

[20] A. L. McGill and P. Anand, "The Effect of Vivid Attributes on the Evaluation of Alternatives: The Role of Differential Attention and Cognitive Elaboration,” Journal of consumer Research, Vol. 16, No. 2, 1989, pp. 188-196. doi:10.1086/209207

[21] G. Biehal and D. Chakravarti, “Consumers' Use of Memory and External Information in Choice: Macro and Micro Perspectives,” Journal of Consumer Research, Vol. 12, No. 4, 1986, pp. 382-405. doi:10.1086/208525

[22] D. Bowman and D. Narayandas, "Managing CustomerInitiated Contacts with Manufacturers: The Impact on Share of Category Requirements and Word of Mouth Behavior," Journal of Marketing Research, Vol. 38, No. 8, 2001, pp. 281-298. doi:10.1509/jmkr.38.3.281.18863

[23] T. Mazzarol, J. C. Sweeney and G. N. Soutar, "Conceptualizing Word-of-Mouth Activity, Triggers and Conditions: An Exploratory Study,” European Journal of Marketing, Vol. 41, No. 11-12, 2010, pp. 1475-1494. doi:10.1108/03090560710821260

[24] R. E. Burnkrant and H. R. Unnava, "Effects of Self-Referencing on Persuasion," Journal of Consumer Research, Vol. 22, No. 1, 1995, pp. 17-26. doi:10.1086/209432

[25] S. P. Jain and D. Maheswaran, "Motivated Reasoning: A Depth-of-Processing Perspective," Journal of Consumer Research, Vol. 26, No. 4, 2000, pp. 358-371. doi:10.1086/209568

[26] P. F. Bone, "Word-of-Mouth Effects on Short-Term and Long-Term Product Judgments," Journal of Business Research, Vol. 32, No. 4, 1995, pp. 213-223. doi:10.1016/0148-2963(94)00047-I

[27] J. L. Giese, E. R. Spangenberg and A. E. Crowley, "Effects of Product-Specific Word-of-Mouth Communication on Product Category Involvement," Marketing Letters, Vol. 7, No. 2, 1996, pp. 187-199. doi:10.1007/BF00434909

[28] C. Avery, P. Resnich and R. Zeckhauser, "The Market for Evaluations,” American Economics Research, Vol. 89, No. 3, 1999, pp. 564-584. doi:10.1257/aer.89.3.564

[29] D. Smith, S. Menon and K. Sivakumar, “Online Peer and
Editorial Recommendations, Trust, and Choice in Virtual Markets,” Journal of Interactive Marketing, Vol. 19, No. 3, 2005, pp. 15-37. doi:10.1002/dir.20041

[30] H. H. Kuan and G. W. Bock, “Trust Transference in Brick and Click Retailers: An Investigation of the BeforeOnline-Visit Phase,” Information \& Management, Vol. 44, No. 2, 2007, pp. 175-187. doi:10.1016/j.im.2006.12.002

[31] M. Y. Cheung, C. Luo, C. L. Sia and H. P. Chen, "Credibility of Electronic Word-of-Mouth: Informational and Normative Determinants of Online Consumer Recommendations," International Journal of Electronic Commerce, Vol. 13, No. 4, 2009, pp. 9-38. doi:10.2753/JEC1086-4415130402

[32] S. J. Yoon, "The Antecedents and Consequences of Trust in Online Purchase Decisions," Journal of Interactive Marketing, Vol. 16, No. 2, 2002, pp. 47-63. doi:10.1002/dir.10008

[33] H. S. Bansal and P. A. Voyer, "Word-of-Mouth Processes within a Services Purchase Decision Context," Journal of Service Research, Vol. 3, No. 2, 2000, pp. 166-177. doi:10.1177/109467050032005

[34] F. von Wangenheim and T. Bayon, "The Effect of Word of Mouth on Service Switching," European Journal of Marketing, Vol. 38, No. 9-10, 2004, pp. 1173-1185. doi:10.1108/03090560410548924

[35] R. E. Burnkrant and A. Cousineau, "Informational and Normative Social Influence in Buyer Behavior,” Journal of Consumer Research, Vol. 2, No. 3, 1975, pp. 206-215. doi:10.1086/208633

[36] M. F. Kaplan and C. E. Miller, “Group Decision Making and Normative versus Informational Influence: Effects of Type of Issue and Assigned Decision Rule," Journal of Personality and Social Psychology, Vol. 53, No. 2, 1987, pp. 306-313. doi:10.1037/0022-3514.53.2.306

[37] C. J. Wakslak, S. Nussbaum, N. Liberman and Y. Trope, "Representations of the Self in the Near and Distant Future," Journal of Personality and Social Psychology, Vol. 95, No. 4, 2008, pp. 757-773. doi:10.1037/a0012939

[38] R. L. Nabi and A. Hendriks, "The Persuasive Effect of Host and Audience Reaction Shots in Television Talk Shows," Journal of Communication, Vol. 53, No. 3, 2003, pp. 527-543. doi:10.1111/j.1460-2466.2003.tb02606.x

[39] T. H. Walvis, "Three Laws of Branding: Neuroscientific Foundations of Effective Brand Building," Journal of Brand Management, Vol. 16, 2008, pp. 176-194. doi:10.1057/palgrave.bm.2550139

[40] M. C. Price and E. Norman, "Intuitive Decisions on the Fringes of Consciousness: Are They Conscious and Does It Matter?” Judgment and Decision Making, Vol. 3, No. 1, 2008, pp. 28-41.

[41] R. Algesheimer, U. M. Dholakia and A. Herrmann, “The Social Influence of Brand Community: Evidence from European Car Clubs,” Journal of Marketing, Vol. 69, No. 3, 2005, pp. 19-34. doi:10.1509/jmkg.69.3.19.66363

[42] D. Lee, H. S. Kim and J. K. Kim, “The Impact of Online Brand Community Type on Consumer's Community Engagement Behaviors: Consumer-created vs. MarketerCreated Online Brand Community in Online Social-Net- 
working Web Sites," Cyberpsychologo Behavior, and Social Networking, Vol. 14, No. 4(1-2), 2011, pp. 59-63.

[43] I. Liviatan, Y. Trope and N. Liberman, "Interpersonal Similarity as a Social Distance Dimension: Implications for Perception of Others' Actions," Journal of Experimental Social Psychology, Vol. 44, No. 5, 2008, pp. 12561269. doi:10.1016/i.jesp.2008.04.007

[44] N. Liberman, M. Sagristano and Y. Trope, "The Effect of Temporal Distance on Level of Mental Construal," Journal of Experimental Social Psychology, Vol. 38, No. 6, 2002, pp. 523-534. doi:10.1016/S0022-1031(02)00535-8

[45] G. R. Semin and K. Fiedler, "The Cognitive Functions of Linguistic Categories in Describing Persons: Social Cognition and Language," Journal of Personality and Social Psychology, Vol. 54, No. 4, 1988, pp. 558-568. doi:10.1037/0022-3514.54.4.558

[46] K. Fujita, Y. Trope, N. Liberman and M. Levin-Sagi, "Construal Levels and Self-Control," Journal of Personality and Social Psychology, Vol. 90, No. 3, 2006, pp. 351-367. doi:10.1037/0022-3514.90.3.351

[47] P. K. Smith and Y. Trope, "You Focus on the Forest When You're in Charge of the Trees: Power Priming and Abstract Information Processing," Journal of Personality and Social Psychology, Vol. 90, No. 4, 2006, pp. 578-596. doi:10.1037/0022-3514.90.4.578

[48] R. W. White, B. Kules, S. M. Drucker and M. C. Schraefel, "Supporting Exploratory Search, Introduction, Special Issue, Communications of the ACM," Communications of The ACM, Vol. 49, No. 4, 2006, pp. 36-39. doi:10.1145/1121949.1121978

[49] R. L. Oliver, "Effect of Expectation and Disconfirmation on Postexposure Product Evaluations: An Alternative Interpretation,” Journal of Applied Psychology, Vol. 62, No. 4, 1977, pp. 480-486. doi:10.1037/0021-9010.62.4.480

[50] R. L. Oliver, "A Cognitive Model of the Antecedents and Consequences of Satisfaction Decisions," Journal of Marketing Research, Vol. 17, No. 4, 1980, pp. 460-469. doi:10.2307/3150499

[51] P. K. Kopalle and D. R. Lehmann, "Strategic Management of Expectations: The Role of Disconfirmation Sensitivity and Perfectionism," Journal of Marketing Research, Vol. 38, No. 3, 2001, pp. 386-394. doi:10.1509/jmkr.38.3.386.18862

[52] D. M. Szymanski and D. H. Henard, "Customer Satisfaction: A Meta-Analysis of the Empirical Evidence,” Journal of the Academy of Marketing Science, Vol. 29, No. 1, 2001, pp. 16-35.

[53] J. L. Walker, "Service Encounter Satisfaction: Conceptualized," Journal of Services Marketing, Vol. 9, No. 1, 1995, pp. 5-14. doi:10.1108/08876049510079844
[54] W. J. Kettinger and C. C. Lee, "Zones of Tolerance: Alternative Scales for Measuring Information Systems Service Quality,” MIS Quarterly, Vol. 29, No. 4, 2005, pp. 607-621.

[55] D. M. Phillips and H. Baumgartner, "The Role of Consumption Emotions in the Satisfaction Response," Journal of Consumer Psychology, Vol. 12, No. 3, 2002, pp. 243-252. doi:10.1207/S15327663JCP1203 06

[56] P. W. Hom, R. W. Griffeth, L. E. Palich and J. S. Bracker, "An Exploratory Investigation into Theoretical Mechanisms Underlying Realistic Job Previews,” Personnel Psychology, Vol. 51, No. 2, 1998, pp. 421-451. doi:10.1111/j.1744-6570.1998.tb00732.x

[57] P. W. Hom, R. W. Griffeth, L. E. Palich and J. S. Bracker, "Revisiting Met Expectations as a Reason Why Realistic Job Previews Work,” Personnel Psychology, Vol. 52, No. 1, 1999, pp. 97-98. doi:10.1111/j.1744-6570.1999.tb01815.x

[58] R. L. Oliver and W. S. DeSarbo, "Response Determinants in Satisfaction Judgments," Journal of Consumer Research, Vol. 14, No. 4, 1988, pp. 495-507. doi:10.1086/209131

[59] R. L. Oliver, P. V. S. Balakrishnan and B. Barry, “Outcome Satisfaction in Negotiation: A Test of Expectancy Disconfirmation," Organizational Behavior and Human Decision Processes, Vol. 60, No. 2, 1994, pp. 252-275. doi:10.1006/obhd.1994.1083

[60] E. A. Locke and R. J. Whiting, "Sources of Satisfaction and Dissatisfaction among Solid Waste Management Employees,” Journal of Applied Psychology, Vol. 59, No. 2, 1974, pp. 145-156. doi:10.1037/h0036531

[61] R. Knoop, “Work Values and Job Satisfaction,” Journal of Psychology, Vol. 128, No. 6, 1994, pp. 683-690. doi:10.1080/00223980.1994.9921297

[62] F. Hebzberg, B. Mausneb and B. Snydebman, "The Motivation to Work," 2nd Edition, John Wiley and Sons, New York, 1959.

[63] V. Shankar, G. L. Urban and F. Sultan, “Online Trust: A Stakeholder Perspective, Concepts, Implications and Future Directions," Journal of Strategic Information Systems, Vol. 11, No. 3-4, 2002, pp. 325-344. doi:10.1016/S0963-8687(02)00022-7

[64] R. Batra, J. G. Myers and D. A. Aaker, "Group Influence and Word-of-Mouth Advertising,” In: R. Batra, J. G. Myers and D. A. Aaker, Eds., Advertising Management, 5th Edition, Prentice Hall, New Jersey, Inc., 1995, pp. 345-363.

[65] D. S. Sundaram, K. Mitra and C. Webster, "Word-of- Mouth Communications: A Motivational Analysis,” Advances in Consumer Research, Vol. 25, No. 1, 1998, pp. 527-531. 